\title{
Multiple Business Goals and Multiple Business InStruments: ThE APPLICATION OF THE THEORY OF Macroeconomic Policy to Business Decisions
}

\author{
Beheruz N. Sethna \\ Larry Allen \\ Dee Wellan \\ Lamar University \\ Beaumont, Texas

\section{Introduction}

A manager is often called upon to make decisions regarding the allocation of scarce resources between two or more business, management, or marketing instruments in order to be able to achieve a certain goal. The analysis of such a problem is not new to business. However, when there is more than one goal to be achieved, each of which is dependent upon a set of business, management, or marketing instruments, the problem is much more complex.

The purposes of this paper are to:

- Analyze the situation of multiple business instruments being used to achieve multiple business goals, using selected principles of macroeconomics,

- To present recommendations for the use of such instruments that suggest that instruments with comparative advantage should be selected to achieve each goal, and

- To illustrate how violation of the principles presented in the paper might lead to undesirable results.

The theory of economic policy may effectively be used to understand and help resolve such problems without restricting the form of the function as multivariate statistical methods usually require. An additional advantage is that it provides a dynamic analysis rather than a comparative-static one. The present work is essentially an application to business or management, of the theory of macroeconomic policy in a multiple goal, multiple instrument setting.

Tinbergen [7], a pioneer of economic policy in a multiple goal and instrument context, developed the Tinbergen principle, which states that the number of policy instruments nust be equal to the number of goals if all the goals are to be achieved. This applies in the context of a fixed target value for each goal, as is common in business

The first author wishes to acknowledge the assistance of Dr. Sonmez Atesoglu, Professor of Economics at Clarkson Univesrity, in the early stages of the paper. 
practice. If the decision-maker can make a trade-off between goals, then the instruments are only required to be less than or equal to the number of goals. This is the case of variable targets, as discussed by Tinbergen [6] and by Theil [5]. The variable targets approach requires the policy maker to be able to specify a continuous trade-off function (like the utility function) between the two goals. Although some trade-off is possible between goals, such a "utility function" is difficult (at best) to specify in management practice. It is much more probable that a manager is required to meet specific fixed target values in particular target or goal areas, such as profit (\$X per unit), market share (Y\%), etc. Consequently, the fixed targets approach is more applied even in actual economic policy issues. For the above reasons, it is the fixed targets situation that is analyzed in this paper.

A major application of the fixed targets approach was presented by Mundell [3, pp. 70-77]. Mundell's principle of effective market classification states that policy instruments should be aimed at the goals on which they have the greatest influence, or in other words, the greatest comparative advantage. In his review of Mundell's analysis of this principle in the context of the use of monetary and fiscal policy (two instruments) to achieve internal and external economic equilibrium (two goals), Makin has observed that, while Mundell's basic principle seems reasonable enough, "it is not immediately obvious that its violation can lead to rather disastrous results [2, pp. 460-461]."

The current work makes use of the fact that there are different effects on goals of the various business instruments controlled by a manager. Such effects were found by Stowsand and Wenzel [4, pp. 243-257] in eight different product groups. Also, Cronin and Skinner [1, pp. 9-22] found that several business instruments (ROA, liquidity, leverage, etc.) had different effects on business outcomes (profitability, financial structure, and marketing outcomes).

In this paper, the above analysis of macroeconomic policy will be applied in a business context to assist in dynamic analysis of the problem of multiple business goals and multiple business instruments. The conclusions of the analysis will be shown to be consistent with good business practice. It will also be demonstrated how failure to conform to the derived guidelines may lead to "disastrous" results.

\section{Analysis}

Consider the case of a brand for which the manager must determine the appropriate business strategy. There are many instruments of strategy available to the manager, and any or all of the elements of the marketing mix may be used to achieve a particular target or goal.

In deciding the business plan for the brand, the manager may allocate resources between the instruments he or she controls, depending upon their relative effect on the brand. Such an analysis of effects, whether intuitively done or based on multivariate analysis, is not new to the field of business. However, when two or more (sometimes conflicting) targets have to be met, the problem is much more complex. It is this problem that is analyzed here. 
For the purpose of this analysis, consider two instruments:

1. Unit Price (P) of the brand,

2. Advertising expenditure (A) per sales period.

Only two business instruments have been chosen for convenience of illustration. The mathematical analysis is generalizable and may be extended to any number of instruments. Any or all of the instruments that a manager controls, including the elements of the marketing mix, may be used.

In this paper, the analysis is concerned with the meeting of two goals:

1. Per Unit Profit (C),

2. Share of Market (at the end of the sales period) (M).

These two target areas have been chosen because of their importance and the frequency of their occurrence in business practice; and because they often require conflicting inputs, which makes the problem more interesting. As in the case of the instruments, the analysis is generalizable and may be extended to any number of targets. Note that the design is consistent with the Tinbergen principle which states that where there are fixed target values for policy goals, the number of policy instruments must be equal to the number of goals if all the goals are to be obtained.

Suppose that a target profit per unit for the brand is set at $\mathrm{C}^{*}$ (dollars) and that the desired market share is targeted at $\mathbf{M}^{*}$. These targets may be determined at any level of the company. For example, the target profit, $\mathrm{C}^{*}$ may be $\$ 1$ per unit for a relatively low-price, high-frequency consumer purchase item; and the target market share $M^{*}$ may be $10 \%$. These figures are only illustrations and would be vastly different for industrial goods or other products.

Each of the two target areas are affected by the two business instruments mentioned above. These may be expressed in a completely general form as:

$$
C=f(P, A)
$$

or, in other words, Per Unit Profit is some (linear or non-linear) function of Unit Price and Advertising Expenditure and

$$
\mathbf{M}=\mathbf{f}(\mathbf{P}, \mathbf{A})
$$

or, in other words, Market Share is some (linear or non-linear) function of Unit Price and Advertising Expenditure. 
where:

$$
\begin{aligned}
& \mathbf{C}=\text { Per Unit Profit } \\
& \mathbf{M}=\text { Market Share } \\
& \mathbf{P}=\text { Unit Price } \\
& \mathbf{A}=\text { Advertising Expenditure }
\end{aligned}
$$

Further, it appears reasonable to assume that, for many products; as price increases, with other variables being held constant (ceteris paribus):

- Per unit profit increases, at least in the short term, because more money is available for the bottom line.

- Market share decreases, since customers buy less of that brand and more of competing brands or products. This is the case of the classic downward-sloping demand curve, often (though not always) found in practice.

As advertising expenditure increases with other variables being held constant:

- Per unit profit decreases, since less money is available for the bottom line

- Market share increases (assuming that the advertising is any good) because more people are made aware of the brand, acquire more knowledge of the brand, and perhaps are persuaded to buy the brand.

Expressions (1) through (6) are quite acceptable intuitively and have been found to be substantiated by numerous academic and corporate findings. They are working assumptions only; violation of these will not invalidate the procedure (although the results will be modified accordingly).

We use the notation $M_{A}$ to denote the incremental change in market share (M) resulting from a unitary change in advertising, with all other variables remaining constant. Graphically, it may be thought of as the slope of the market share (M) line with respect to advertising expenditure (A). (For those readers more comfortable with calculus, $M_{A}$ is the partial derivative of $M$ with respect to $A, \delta M / \delta A$.) Similarly, we use the notation $M_{P}$ to denote the incremental change in market share (M) resulting from a unitary change in price, with all other variables remaining constant). Graphically, it may be thought of as the slope of the market share (M) line with respect to price (P). $\left(M_{P}\right.$ is the partial derivative of $M$ with respect to $P, \delta M / \delta P$.)

In business practice, the usual way of determining the incremental effect of one variable upon another is to do an empirically-based analysis. For example, a regression analysis may be done with Market Share $(M)$ as the dependent variable, and Advertising Expenditure (A) and Price (P) as the independent variables. Then, the regression coefficients for $A$ and $P$ represent $M_{A}$ and $M_{P}$ respectively, because they represent the incremental change in $M$ resulting from incremental changes in $A$ and $P$ respectively, with the other variable being held constant. 
We can then rephrase Expressions (3) through (6), using the above notation for the sake of brevity:

As price increases, profit increases, so

As price increases, market share decreases, so

As advertising increases, profit decreases, so

As advertising increases, market share increases, so

$\mathrm{C}_{\mathrm{P}}>0$
$\mathrm{M}_{\mathrm{P}}<0$
$\mathrm{C}_{\mathrm{A}}<0$
$\mathrm{M}_{\mathrm{A}}>0$

Given that both business instruments (price, $P$, and advertising, A) affect goals (per unit profit, $C$, and market share, $M$ ), we can find various combinations of $P$ and $A$ that can achieve together levels of $C$ and $M$.

For example, if our targeted market share is $M^{*}$ or $10 \%$, it may be that a price of $\$ 5$ per unit and advertising expenditure of $\$ 40,000$ per year may achieve this target. Now if we increase the price to $\$ 6$, market share may be in danger of dropping below the desired $10 \%$ level. However, by increasing the advertising level to say, $\$ 45,000$ per year, (perhaps singing the praises of an upscale brand) the manager may be able to avert any decline of market share, leaving $M$ at the desired $10 \%$ level. So, we now have two combinations of $P$ and $A$ that lead to the desired market share, $M^{*}$ or 10\%: these are $(P=\$ 5$ and $A=\$ 40,000)$ and $(P=\$ 6$ and $A=\$ 45,000)$. Similarly, several other combinations of $P$ and $A$ may be found; for example ( $P=\$ 6.50$ and $A=\$ 55,000)$, $(P=\$ 4$ and $A=\$ 30,000)$, etc. may also result ia a market share of $10 \%$. Note that, as we increase price, we must increase advertising (and vice versa) to remain at the desired level of market share. This is a result of the basic relationships discussed in Expressions (3) - (6); the numbers, however, are for illustrative purposes only.

The verbal arguments in the preceding paragraph lead to the generalizable result that several combinations of $P$ and $A$ may be found, that lead to the targeted value, $M^{*}$, of market share. These combinations of $P$ and $A$ may be found experimentally or mathematically (by use of the calculus) once Expressions (1) and (2) are empirically determined. For example, regression analysis on corporate data with Market Share as the dependent variable and Price and Advertising Expenditure as independent variables is one way of empirically determining Expression (2): $M=f(P, A)$.

In a similar vein, different combinations or trade-offs between $P$ and $A$ can lead to the desired per unit profit, $C^{*}$. For example, if a price of $\$ 4.50$ and advertising of $\$ 38,000$ per year achieve the desired per unit profit of $\$ 1$, we may be able to retain that $\$ 1$ profit per unit by simultaneously increasing the price to $\$ 5.00$ and increasing the advertising to $\$ 40,000$. Note that, as in the analysis of market share, an increase of price must be combined with an increase in advertising (and vice versa) to preserve the targeted per unit profit $\mathrm{C}^{*}$.

Figure 1 shows two lines: $\mathrm{C}=\mathrm{C}^{*}$ and represents the combination of $\mathrm{P}$ and $\mathrm{A}$ that lead to the targeted per unit profit of $C^{*}$, and $M=M^{*}$ represent the combinations of $P$ and $A$ that yield the targeted market share of $\mathbf{M}^{*}$. Note that both lines slope upwards; this is consistent with the conclusions of the preceding paragraphs that showed that, to preserve the targeted levels of $\mathrm{C}^{*}$ and $\mathrm{M}^{*}$, if we increase $\mathrm{P}$ we must increase $\mathrm{A}$, and vice versa. 


\section{Figure 1}

Case 1: Assumes Comparative Advantage for Advertising in Affecting Market Share and for Price in Affecting Profit

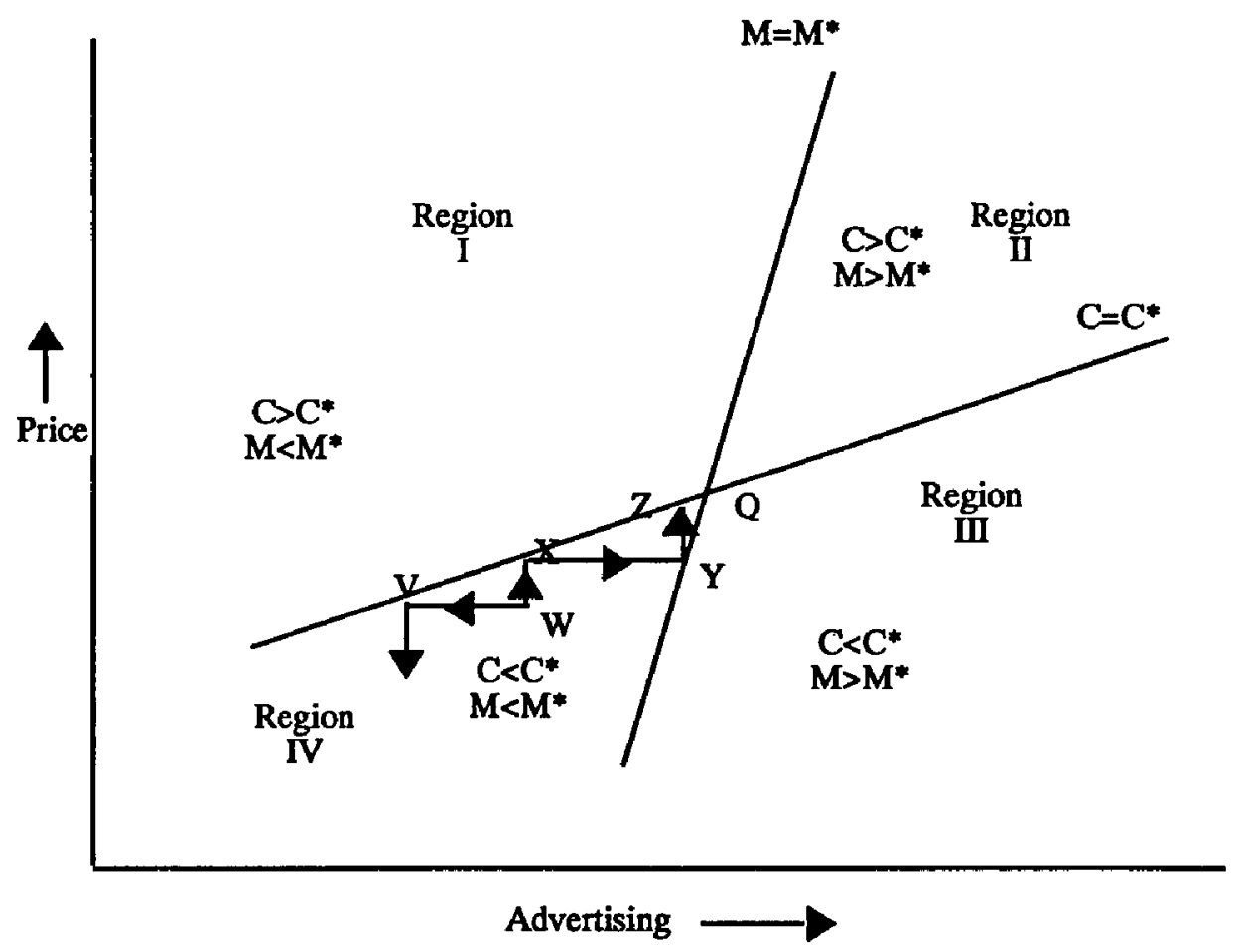

Figure 1 is drawn such that the slope of the $M=M^{*}$ line is greater than the slope of the $\mathrm{C}=\mathrm{C}^{*}$ line. This is a representation of comparative advantage for advertising in affecting market share and for price in affecting profit. That is, market share is more sensitive to advertising expenditure changes than to price changes. The justification for the preceding statement is not immediately obvious and may be provided by a mathematical justification using differential calculus or by using graphical and verbal arguments. The latter approach is favored here and is described in the following paragraphs.

If advertising expenditure has a relatively large effect on market share (M) and price has a small effect on $M$, we might expect the following to occur. As an example, let us start with one of the points of the $M=M^{*}$ line: let us say that the targeted market share of $10 \%$ is achieved when Price $(P)=\$ 5$ per unit and Advertising $(A)=\$ 40,000$ per year. Now, if we increase the price to $\$ 6$ (a $20 \%$ increase), that would, ceteris paribus, lead to a loss of customers because of the downward-sloping demand curve. To prevent this from occurring, we increase advertising. If advertising has a large 
relative effect on market share, we may need to increase advertising only by, say, $\$ 1,000$ (a $2.5 \%$ increase; this high impact of advertising is exaggerated for illustration). So to move from one point on the $M=M^{*}$ line to another point, we have a relatively large movement on the $\mathbf{P}$ (price) dimension for a relatively small movement on the A (Advertising) dimension. This corresponds to the relatively steep slope of the $M=M^{*}$ line in Figure 1.

Further, if price has a relatively large effect on per unit profit $(\mathrm{C})$ and advertising a relatively small effect or $\mathrm{C}$, we might expect the following scenario. As an illustration, we consider one of the points on the $C=C^{*}$ line: price $(P)=\$ 4.50$ and advertising $(\mathrm{A})=\$ 35,000$ per year. Now, if price has a relatively large effect on profit (because of the product's cost structure), and we increase price to $\$ 5$ (approximately an $11 \%$ increase), we may be able to remain at our desired profit level even in spite of a relatively large increase in advertising, say, by $\$ 7,000$ (a $20 \%$ increase). So, to move from one point on the $\mathrm{C}=\mathrm{C}^{*}$ line to another, we have a small increase in $\mathrm{P}$ accompanied by a large increase in $A$. This shows up as a low slope for the $C=C^{*}$ line in Figure 1.

Figure 1, then, represents a case where advertising has a high effect (relative to price) on market share, and price has a high effect (relative to advertising) on per unit profit. This is the case of comparative advantage for advertising in affecting market share and for price in affecting per unit profit. The reverse case will be discussed later (Figure 2).

Figure 1 may be divided into four regions formed by the intersection of the $M=M^{*}$ and $\mathrm{C}=\mathrm{C}^{*}$ lines. These are labeled Regions I, II, III, and IV. For any value of advertising, a point above the $\mathrm{C}=\mathrm{C}^{*}$ line represents a higher price than the one that achieves the desired per unit profit; it therefore represents a profit higher than $\mathrm{C}^{*}$ (since, as price increases, ceteris paribus, so does per unit profit). So all points above the line $C=C^{*}$ represent values of $C$ which are greater than $C^{*}$. Hence, Regions I and II are labelled as $\mathrm{C}>\mathrm{C}^{*}$. Correspondingly, points below the line $\mathrm{C}=\mathrm{C}^{*}$ (Regions III and

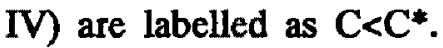

In a similar manner, for any value of price, note that points to the right of the line $\mathbf{M}=\mathbf{M}^{*}$ represent values of advertising which is greater than the value necessary to achieve targeted market share, $\mathbf{M}^{*}$. Since, ceteris paribus, as advertising increases, market share increases, values of market share to the right of the line $\mathrm{M}^{-M^{*}}$ represent market share values greater than $\mathbf{M}^{*}$. So, Regions II and III are labelled as $\mathbf{M}>\mathbf{M}^{*}$. Correspondingly, Regions I and IV are labelled as $M<M^{*}$.

Each of the four regions bounded by the lines $C=C^{*}$ and $M=M^{*}$ may be classified as $\mathrm{C}>\mathrm{C}^{*}$ or $\mathrm{C}<\mathrm{C}^{*}$, and $\mathrm{M}>\mathrm{M}^{*}$ or $\mathrm{M}<\mathrm{M}^{*}$. Three of these regions (I, III, and IV) represent a strategy problem for the manager, because one or both of the target areas falls short of the target. For example, in Region I, though profit is greater than the target $\left(C>C^{*}\right)$, market share is less than the target $\left(M<M^{*}\right)$. An attempt to bring the "deficient" area on target may cause the other one to fall short of the target, because of the nature of the business problem chosen for study, since what is good for market share may be bad for per unit profit and vice versa. 
According to the Tinbergen principle, since the manager has two targets, $C^{*}$ and $\mathbf{M}^{*}$, and two business instruments, $P$ and $A$, under his or her control, it is possible to achieve both targets simultaneously (assuming reasonable targets). However, according to Mundell's principle of effective market classification, this simultaneous achievement (overall equilibrium), though possible, need not necessarily be achieved unless his principle is followed. Mundell's principle, repeated here for convenience, states that instruments should be aimed at target areas on which they have the maximum influence or comparative advantage. Though this principle seems intuitively quite obvious, it is not as obvious that violation of the principle may lead to disastrous results. These points are illustrated below in the context of Figure 1, using a dynamic business analysis.

If, for example, the manager faces a situation where both, per unit profit and market share, fall below the targeted values (Region IV, indicated by $C<C^{*}, M^{*} M^{*}$ ), a dilemma exists. The need for higher (per unit) profit implies cutting back on business inputs (decrease advertising and increase price), whereas the need for higher market share implies allocating more funds into business inputs (increase advertising and decrease price). According to Tinbergen's principle (according to business understanding as well), a judicious combination of pricing and advertising policies can be found so that both targets may be achieved (assuming realistic targets), i.e. the combination of $\mathbf{P}$ and $\mathbf{A}$ corresponding to point $\mathbf{Q}$ in Figure 1 .

A comparative-static analysis would be content to state that the use of the two instruments can move the brand from any other point to $Q$. Such an analysis tells the manager where to go (to $\mathrm{Q}$ ). A regression analysis, or other quantitative tools in an empirical study, may show the "correct" slopes or signs on the coefficients $\left(C_{P}>0\right.$, $C_{A}<0, M_{P}<0, M_{A}>0$, as described Expressions (7) - (10)), which implies that either instrument may be used to achieve either goal. However, this approach may lead to potentially disastrous results, as the following analysis will show.

As mentioned earlier, $C_{A}$ is the notation used to denote the incremental change in profit from a unitary change in advertising, with all other variables remaining constant. It may be thought of as the slope of the per unit profit $(C)$ line with respect to advertising expenditure (A). Alternatively, it is the partial derivative of $C$ with respect to A. Let us assume that, as stated in Expression (9), we find that $C_{A}<0$ based on an empirical study. This coefficient implies that, ceteris paribus, we expect a decrease in $C$ if $A$ increases, and vice versa.

In Figure 1, consider Point $W$ where $C<C^{*}$ and $M<M^{*}$. If the principle of effective market classification is violated or ignored, very undesirable results may result. In order to increase per unit profit, advertising is cut back to a level corresponding to $\mathrm{V}$ which, in fact, decreases market share. In order to increase market share, price is decreased (since the empirical study showed the commonly-found result of $M_{P}<$ 0 ), moving the brand further away from the desired target. Here, it does not matter which comes first - the advertising cut-back or the price decrease; the result is not an expected or desirable one, in spite of the above (intrinsically sound) business strategies. 
Let us now consider using Mundell's principle, which is concerned with the dynamic analysis - the method to be followed to achieve the targets. Since price has the comparative advantage in affecting $\mathrm{C}$, Mundell's principle would suggest increasing price to that corresponding to $\mathrm{X}$ where $\mathrm{C}=\mathrm{C}^{*}$. Since advertising has the comparative advantage in influencing $M$, the principle would suggest that advertising be increased to that corresponding to $Y\left(M=M^{*}\right)$ so that the brand may be moved from $X$ to $Y$. In a similar fashion, by price and advertising increases, the brand can move towards $Q$ and so achieve both targets. There is no theoretical significance to starting with a price increase. In a given business situation, it may be more appropriate to start with an increase in advertising input.

It must be emphasized that these results occur because of the relative comparative advantages of price and advertising in affecting the two target areas (profit and market share) represented by the relative slopes of the two lines, $C=C^{*}$ and $M=M^{*}$, in Figure 1. The opposite case would arise if the comparative advantages were reversed. This is discussed in Case 2, which follows.

\section{Figure 2}

Case 2: Assumes Comparative Advantage for Advertising in Affecting Profit and for Price in Affecting Market Share

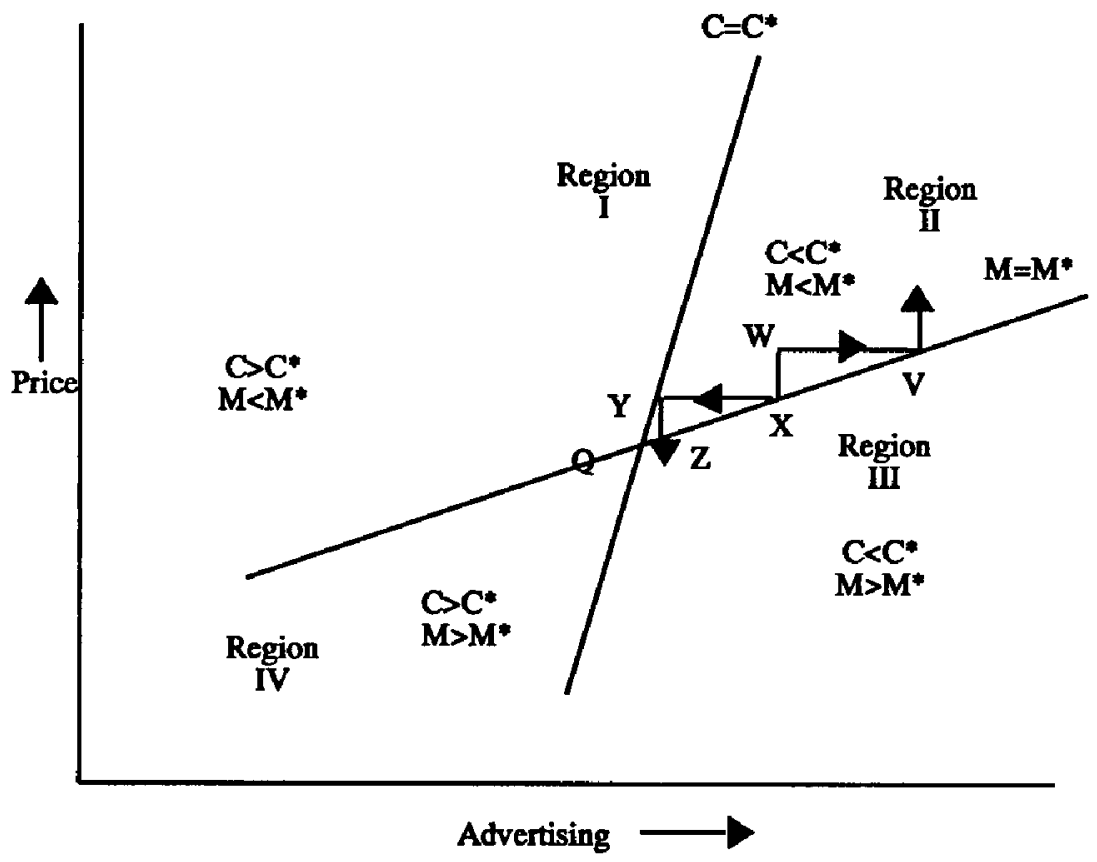

Figure 2 is divided into four regions, bounded by the lines $C=C^{*}$ and $M=M^{*}$, respectively. Each one of these regions (except for Region IV, in which $\mathrm{C}>\mathrm{C}^{*}, \mathbf{M}>\mathbf{M}^{*}$ ) 
represents a strategy problem because at least one target is not met. Consider, for example, the dilemma faced by the manager in Region II represented by $C<C^{*}, M<M^{*}$ (Case 1).

Figure 2 is similar to Figure 1 , except for the relative slopes of the $C=C^{*}$ and $\mathbf{M}=\mathbf{M}^{*}$ lines. Figure 2 assumes a comparative advantage for price in affecting market share and for advertising in affecting profit. This is the opposite case to Case 1 (and Figure 1).

As in Case 1, Mundell's principle of comparative advantage is used to suggest a dynamic analysis to achieve both targets simultaneously. Since price has the comparative advantage in influencing market share, and advertising in affecting profit, the principle would suggest using appropriate price decreases (to increase $M$ ) combined with appropriate advertising cuts (to increase $C$ ) so as to move the brand along the path $\mathbf{W} \rightarrow \mathbf{X} \rightarrow \mathbf{Y} \rightarrow \mathbf{Z}$, and so on until the targets are met (approached) at point $\mathbf{Q}$. (As in Case 1, an advertising cut-back may precede the price decrease.)

If, however, Mundell's principle is violated, the result will be disastrous. If, at the starting point, $W$, the manager only looks for the "correct" signs on the coefficients of price $\left(C_{P}>0\right)$ and advertising $\left(M_{A}>0\right)$, without considering comparative advantage, the advertising input may be increased (in an attempt to increase market share) to a level corresponding to $\mathrm{V}$, then price may be increased (in an attempt to increase profit), moving the brand further and further away from the targets.

\section{Business Implications and Potential Applications}

Two cases were considered in the above analysis: One case in which advertising has the comparative advantage in affecting market share, and the other case in which its comparative advantage is in affecting profit. In fact, they may be taken as being instances of an entire spectrum of cases ranging from an extreme situation where the market share is inelastic to price, and dominated by advertising and other marketing inputs; to the other extreme in which price is the all important instrument in affecting market share.

Case 1 assumed that market share was "dominated" (to a greater or lesser extent) by advertising effects and price was the less dominant influence. Such cases are very common in business practice. This is the case of the premium product (as seen from a product portfolio viewpoint), or the case of a quality product in a price-insensitive market (viewed as segmentation analysis), or the case of the image building task (at initial stage(s) in the product life-cycle), etc. The above examples (in parentheses) are intended only as instances of potential marketing applications. The theoretical analysis showed that the appropriate business strategy, if profit and market share targets are not met, is to increase advertising and price in the indicated manner. This is consistent with business judgment.

Case 2 is representative of the situation in which price has the dominant effect on market share and advertising has relatively little influence. The business applications 
of this case are opposite to the ones mentioned above: the standardized product or market, or a product in the later stage(s) of the life-cycle. The theoretical analysis indicated that the appropriate strategy, if targets were not met, would be decrease price and advertising as shown in Figure 2. This, too, is consistent with business judgment.

The analysis provides a rigorous theoretical base to some commonly held business beliefs. Although the analysis is a general one, it is not any less pragmatic for that reason. The only parameters required for analysis of a specific brand in a particular market are the partial derivatives, $\left(C_{B} C_{A}, M_{B}\right.$ and $\left.M_{A}\right)$ in the cases discussed above. These parameters may be empirically obtained in a given situation. One method for obtaining them is to use the regression coefficients of a regression analysis with Market Share as the dependent variable, for example, and Price and Advertising (lagged, if appropriate) as the independent variables. As shown by Stowsand and Wenzel [5, p. 254] in their study of eight different product groups, and Cronin and Skinner [1, pp. 14-17] in their study of the different effects of several business instruments (ROA, liquidity, leverage, etc.) on business outcomes (profitability, financial structure, and marketing outcomes), different instrument coefficients are obtained that show differing effects on business goals. The current paper provides a normative case for the appropriate use of such analyses.

Some conclusions of the analysis which would not have been immediately obvious without the benefit of this theory are described below:

(a) The fact that the slopes or regression coefficients, $C_{B} C_{A}, M_{B}$ and $M_{A}$, are found to be of the appropriate sign in an empirical study $\left(C_{P}>0, C_{A}<0\right.$, $\left.M_{P}<0, M_{A}>0\right)$ is no indication that either instrument should be used to achieve a particular target. For instance, the analysis indicates that, even if price increases have a positive effect on profit and a negative effect on market share, as expected, it should not be used as a business instrument to affect market share unless it has the comparative advantage.

(b) Violation of the principle of effective market classification leads to disastrous consequences. To continue with the example mentioned in (a) above, if price is used as an instrument to change market share, the brand will move further away from its targets, unless it has the comparative advantage.

Based on the findings of this paper, it is recommended that a manager develop an understanding of the relative strength or comparative advantage of the instruments at his or her command. One method for doing this is through regression analysis, where the regression coefficients are indicators of the relative strength. Other quantitative or accounting data may also help determine such relationships and effects. If no historical data is available, the manager may consider a judgemental analysis based on other similar products inside or outside the company. It is further recommended that the manager use the instrument that has the comparative advantage to achieve each of the goals. 


\section{Summary and Conclusions}

The approach in this paper analyzes the problem of multiple goals and multiple instruments in the business context and provides a rigorous theoretical base for some business strategies; it presents recommendations for the use of such instruments that suggest that instruments with comparative advantage should be selected to achieve each goal; and it illustrates how violation of the principles presented in the paper might lead to undesirable results. The conclusions of the theoretical analysis are shown to be consistent with business judgment. Also shown are some conclusions of the theory which are not immediately obvious, and dangers of violation of the theoretical principles.

The analysis presented in this paper uses a dynamic approach rather than a comparative-static one. In this respect, it adds an additional dimension to the solution of such business problems. This analysis is made possible by incorporating theories of macroeconomic policy into business framework. The resulting expansion of the boundaries of knowledge and integration of two fields (macroeconomics applied to the strategy of the firm) may well be contributions of this paper. The procedure described in this paper is a general one and may be applied to a number of corporate or social goals.

\section{References}

1. Cronin, J.J., Jr. and Skinner, S.J. "Marketing Outcomes, Financial Conditions, and Retail Profit Performance." Joumal of Retailing, Vol. 60, No. 4 (1984) pp. 9-22.

2. Makin, J.H. Macroeconomics. Hinsdale, IL.: The Dryden Press (1975), pp. 460-461.

3. Mundell, R.A. "The Appropriate Use of Monetary and Fiscal Policy for Internal and External Stability." International Monetary Fund, Staff Papers, Vol. 55, No. 3 (March 1962), pp. 401-415.

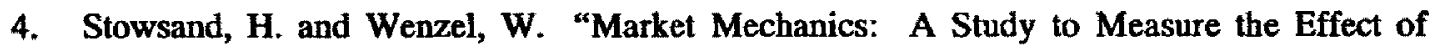
Marketing Instruments on the Market Position of Fast-Moving Consumer Goods." Journal of Business Research, Vol. 7, No. 3 (1979), pp. 243-257.

5. Theil, H. Optimal Decision Rules for Government and Industry. Amsterdam: North Holland (1964).

6. Tinbergen, J. Centralization and Decentralization in Economic Policy. Amsterdam: North Holland (1954).

7. Tinbergen, J. On the Theory of Economic Policy. Amsterdam: North Holland (1951). 